TITLE:

\title{
Conversion of unused heat energy to electricity by means of thermoelectric generation in condenser
}

\author{
AUTHOR(S): \\ Kyono, T; Suzuki, RO; Ono, K
}

\section{CITATION:}

Kyono, T ...[et al]. Conversion of unused heat energy to electricity by means of thermoelectric generation in condenser. IEEE TRANSACTIONS ON ENERGY CONVERSION 2003, 18(2): 330-334

\section{ISSUE DATE:}

2003-06

URL:

http://hdl.handle.net/2433/50277

\section{RIGHT:}

(c)2003 IEEE. Personal use of this material is permitted. However, permission to reprint/republish this material for advertising or promotional purposes or for creating new collective works for resale or redistribution to servers or lists, or to reuse any copyrighted component of this work in other works must be obtained from the IEEE. 


\title{
Conversion of Unused Heat Energy to Electricity by Means of Thermoelectric Generation in Condenser
}

\author{
Takashi Kyono, Ryosuke O. Suzuki, and Katsutoshi Ono
}

\begin{abstract}
Thermoelectric power generation has the potential to recover a large amount of energy loss at the vapor condensers in the steam-based power plants. A suitable arrangement of thermoelectric modules was designed from the heat transfer theory in the cylindrical heat exchanger. Even under the practical operation limits, $150 \mathrm{~kW}$ can be generated by the thermoelectric conversion.
\end{abstract}

Index Terms-Steam-based power plants, surface condenser, thermoelectric energy conversion.

\section{INTRODUCTION}

$\mathbf{M}$ AJOR part of electric energy demands are currently fulfilled by steam-based power plants, such as thermal or nuclear power stations. The efficiency of these plants is at most $40 \%$ and obviously the rest of the energy is unused or lost. The greatest energy loss occurs in the plants' condensers, as the latent heat of condensation. However its retrieval is difficult since the condensation of vapor takes place at low temperature and pressure.

Thermoelectric power generation is adequate for utilizing such low-grade heat and improving the total efficiency of power plants. Thermoelectric generation is a direct and clean heat-to-electricity conversion, and can be operated even if the temperature difference between the heat sources is small [1]. The purpose of this work is to propose the utilization of unused energy in condensers by means of thermoelectric conversion and to calculate a theoretical amount of energy retrieval in a heat exchanger.

\section{FundAMENTALS OF THERMOELECTRIC CONVERSION}

The principles on thermoelectrics are described in [2] and [3]. Brief fundamental equations are shown to introduce the variables used here.

Thermoelectric power is generated by combining a series of p-type and n-type elements. An example is shown in Fig. 1. When temperature difference is applied on this module, the electromotive force developed by one thermoelectric couple $V_{0}$ is given by

$$
V_{0}=\left(\alpha_{p}-\alpha_{n}\right)\left(\theta_{h}-\theta_{c}\right)=\Delta \alpha\left(\theta_{h}-\theta_{c}\right),
$$

where $\alpha_{p}$ and $\alpha_{n}$ are the Seebeck coefficients of p-type and n-type elements, and $\theta_{h}$ and $\theta_{c}$ are the hot and cold junction temperatures, respectively. From here on, the properties with subindex $p$ and $n$ represent p-type and n-type properties, respec-

\footnotetext{
Manuscript received March 7, 2001; January 8, 2002. This work was supported in part by Japan Nuclear Cycle Development Institute.

The authors are with the Department of Energy Science and Technology, Kyoto University, Kyoto, 606-8501, Japan.

Digital Object Identifier 10.1109/TEC.2003.81172
}

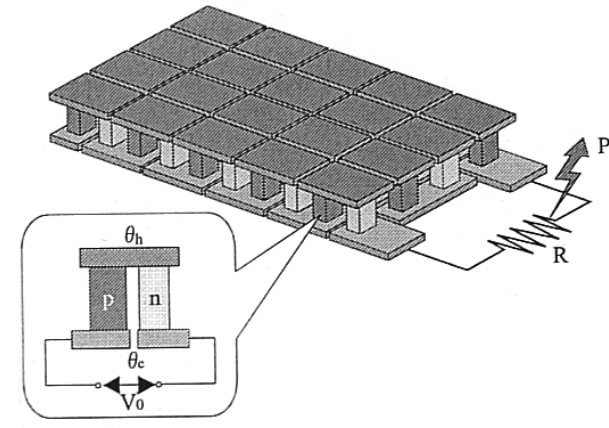

Fig. 1. Schematic illustration of thermoelectric module.

tively. The properties of materials for the thermoelectric couples are generally evaluated by the figure of merit $Z$

$$
Z=\frac{\Delta \alpha^{2}}{\left(\sqrt{\rho_{p} \lambda_{p}}+\sqrt{\rho_{n} \lambda_{n}}\right)^{2}}
$$

where $\rho_{p}$ and $\rho_{n}$ are the resistivities and $\lambda_{p}$, and $\lambda_{n}$ are the thermal conductivities.

The output power $P$ becomes maximum when the inner electrical resistance of the module is equal to the load $R$. The output power $P$ is then represented by

$$
P=\frac{V^{2}}{4 R}=\frac{\left(n V_{0}\right)^{2}}{4 R}
$$

where $V$ is the electromotive force of the whole module, and $n$ is the number of thermoelectric couples.

It is known that the semiconductors such as BiTe or PbTe, or the compounds such as skutterudites have high efficiency to convert heat to electricity. However, they are not appropriate in a large scale application because these alloys are composed with somewhat uncommon materials. $\beta-\mathrm{FeSi}_{2}$ is also a well-known thermoelement as a candidate for an environmentally friendly material, but its performance declines at around room temperature due to its rather high resistivity. For these reasons, the authors proposed to use $\mathrm{Fe}-12.8 \mathrm{wt} \% \mathrm{Al}-12.7 \mathrm{wt} \% \mathrm{Si}$ as p-type elements and $\mathrm{Fe}-12.3 \mathrm{wt} \% \mathrm{Al}$ as n-type elements listed in Table I [4]. These Fe-based alloys possess abundant natural resources and better mechanical properties, which make this concept feasible even if their performances are not as great as the above mentioned semiconductors.

\section{CONCEPT OF THERMOELECTRIC GENERATION IN CONDENSER}

A surface condenser has been mainly used in power plants. It condenses vapor to water at the surface of coolant tubes in 
TABLE I

THERMOELECTRIC PROPERTIES FOR FEALSi AND FEAL AT $300 \mathrm{~K}$

\begin{tabular}{|c|c|c|c|}
\hline & $\begin{array}{c}\text { Seebeck } \\
\text { coefficient } \\
(\mu \mathrm{V} / \mathrm{K})\end{array}$ & $\begin{array}{c}\text { Thermal } \\
\text { conductivity } \\
(\mathrm{W} / \mathrm{m} \cdot \mathrm{K})\end{array}$ & $(\mu \Omega \cdot \mathrm{m})$ \\
\hline FeAlSi (p) & 46 & $11 \pm 3$ & 1.40 \\
\hline $\mathrm{FeAl}(\mathrm{n})$ & -23 & $21 \pm 3$ & 1.01 \\
\hline
\end{tabular}

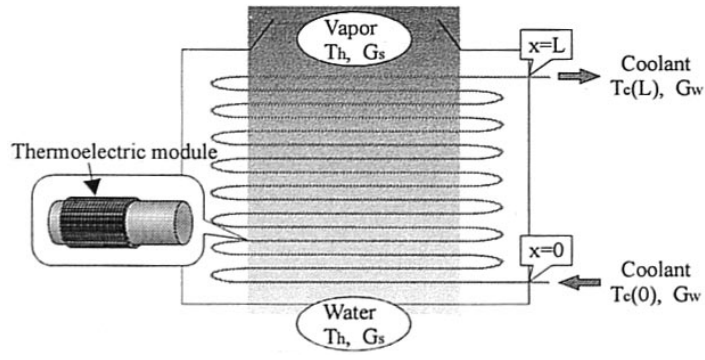

Fig. 2. Model of surface condenser for calculation.

which sea water is flowing as the coolant. The vapor volume decreases drastically in a condenser, resulting in a decrease of pressure down to $25-45 \mathrm{mmHg}$. The vapor temperature put into the condenser is $40^{\circ} \mathrm{C}$ at the highest, and it is kept almost constant during condensation. The temperature of the coolant, sea water, is around $15-19^{\circ} \mathrm{C}$ in Japan. The temperature difference between the vapor and the coolant can be converted to electricity by thermoelectric generation.

\section{CAlculation}

Fig. 2 shows the model of a surface condenser used for calculation. Coolant flows through a winding tube inside the condenser with a mass flow rate of $G_{w}$, exchanging heat with the vapor flow outside the tube (a mass flow rate of $G_{s}$ ). This vapor is assumed to be saturated. The real condenser contains a lot of coolant tubes, but the number of tubes affects only the coolant mass flow in terms of the condenser design. Hence, it is valid and simple to consider one long coolant tube, except when determining the heat transfer coefficient of the coolant. The axial length of the coolant tube from the entrance is expressed as $x$ and the total length as $L$. Considering ideal condensation for vapor-to-water change, the vapor temperature $T_{h}$ remains constant, while the coolant temperature $T_{c}$ becomes a function of $x$. Here, the coolant temperature distribution in the radial direction in a narrow tube is neglected.

The calculation scheme for the output power consists of two heat balance equations. One is the total heat balance in the condenser, which gives the relation between the vapor mass flow $G_{s}$ and the coolant mass flow $G_{w}$. The another is the local heat balance in the coolant tube, which gives the relation between the coolant mass flow $G_{w}$ and the junction temperature difference. These two relations enables us to express the output power $P$ with the vapor mass flow $G_{s}$.

First, the total heat balance in the condenser can be written as

$$
\begin{aligned}
G_{s} \Delta h & =C_{w} G_{w}\left(T_{c}(L)-T_{c}(0)\right) \\
& =C_{w} G_{w} \Delta T_{w}
\end{aligned}
$$

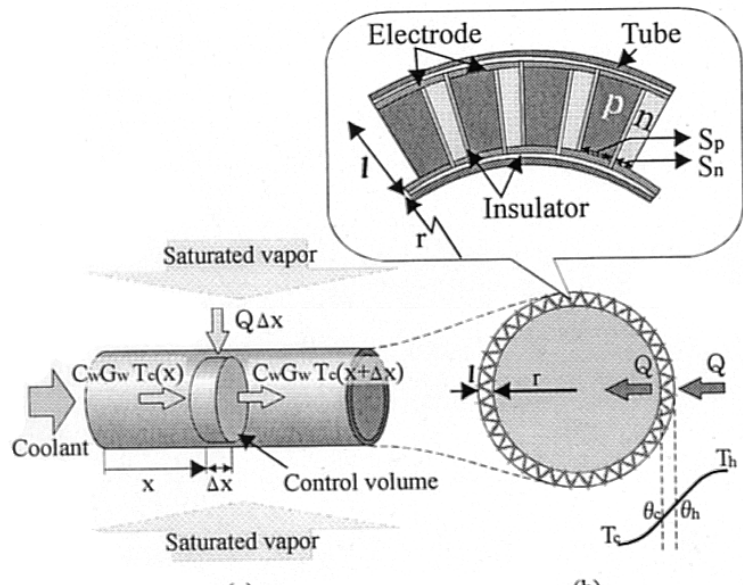

(a)

(b)

Fig. 3. Illustration of (a) coolant tube. (b) Its cross-sectional view.

where $C_{w}$ is the specific heat of the coolant and $\Delta h$ is the latent heat of water. $T_{c}(0)$ and $T_{c}(L)$ are the coolant temperatures at the entrance and the exit of the tube, respectively.

Second, we will develop the local heat balance equations through the wall of the coolant tube. Fig. 3 shows the coolant tube and its cross-sectional view. Here, a thermoelectric module of thickness $l$ is attached to the coolant tube of radius $r$, assuming that the thickness of the electrode and that of the coolant tube can be neglected. The hot and cold junction temperatures of the module are expressed as $\theta_{h}(x)$ and $\theta_{c}(x)$, respectively. The thermal conduction toward the axial direction of the module is neglected because it is much smaller than that toward the radial one. For the simplicity of the calculation and low efficiency of the Fe-based alloy module, the Peltier effect and Jule heat were not taken into account. From such assumptions, the heat input into the module from the outside of the tube becomes equal to the heat output from the inner surface of the tube as shown in Fig. 3(b). The heat transfer from the vapor to the coolant through the annular module per unit length can be written as follows [5]

$$
Q=k\left(T_{h}-T_{c}(x)\right)
$$

where

$$
k=\frac{2 \pi}{\frac{1}{(r+l) h_{h}}+\frac{\ln \left(\frac{r+l}{r}\right)}{\lambda}+\frac{1}{r h_{c}}}
$$

$h_{h}$ and $h_{c}$ are the heat transfer coefficients of the vapor and coolant, respectively. $\lambda$ is the thermal conductivity of the module, given by

$$
\lambda=\frac{\lambda_{p} S_{p}+\lambda_{n} S_{n}}{S_{p}+S_{n}}
$$

where $S_{p}$ and $S_{n}$ are the areas of the thermoelements at the inner surface end.

The following differential equation can be obtained from the heat balance in the control volume shown in Fig. 3(a)

$$
\frac{d T_{c}(x)}{d x}=\frac{k}{C_{w} G_{w}}\left(T_{h}-T_{c}(x)\right) .
$$


Integration of (9) gives the coolant temperature distribution $T_{c}(x)$ and the coolant tube length $L$

$$
\begin{aligned}
T_{h}-T_{c}(x) & =\Delta T_{\text {in }} \exp \left(-\frac{k x}{C_{w} G_{w}}\right) \\
L & =\frac{C_{w} G_{w}}{k} \ln \left(\frac{\Delta T_{\text {in }}}{\Delta T_{\text {out }}}\right)
\end{aligned}
$$

where $\Delta T_{\text {in }}\left(=T_{h}-T_{c}(0)\right)$ is the temperature difference between the vapor and the coolant at the tube entrance, and $\Delta T_{\text {out }}\left(=T_{h}-T_{c}(L)\right)$ is that at the exit. Substituting (6) and (10) into Fourier's law expressed in the cylindrical coordinates, the junction temperature difference can be written as

$$
\begin{aligned}
\theta_{h}(x)-\theta_{c}(x) & =\frac{\ln \left(\frac{r+l}{r}\right)}{2 \pi \lambda} Q \\
& =\frac{k \Delta T_{\text {in }} \ln \left(\frac{r+l}{r}\right)}{2 \pi \lambda} \exp \left(-\frac{k x}{C_{w} G_{w}}\right) .
\end{aligned}
$$

The two relations, (5) and (13), are used for the calculation of the output power. By neglecting the cross-sectional area of the insulator, the number of the thermoelectric couples per unit area $n$ can be expressed as

$$
n=\frac{1}{S_{p}+S_{n}} .
$$

The electromotive force $V$ and the electrical resistance of the module $R$ is calculated as follows:

$$
\begin{aligned}
V & =\int_{0}^{L} \Delta \alpha\left(\theta_{h}(x)-\theta_{c}(x)\right) \cdot 2 \pi r n d x \\
R & =\int_{0}^{L}\left(\rho_{p} \frac{r \ln \left(\frac{r+l}{r}\right)}{S_{p}}+\rho_{n} \frac{r \ln \left(\frac{r+l}{r}\right)}{S_{n}}\right) \cdot 2 \pi r n d x .
\end{aligned}
$$

Substituting (15) and (16) into (3), the output power $P$ is derived as

$$
P=\frac{1}{\left(S_{p}+S_{n}\right)\left(\frac{\rho_{p}}{S_{p}}+\frac{\rho_{n}}{S_{n}}\right) \lambda} \cdot \frac{\Delta \alpha^{2} G_{s} \Delta h k \Delta T_{w} \ln \left(\frac{r+l}{r}\right)}{8 \pi \lambda \ln \left(\frac{\Delta T_{\text {in }}}{\Delta T_{\text {out }}}\right)} .
$$

The first term of (17) is maximized when $S_{p}$ and $S_{n}$ satisfy the following:

$$
\frac{S_{n}}{S_{p}}=\sqrt{\frac{\rho_{n} \lambda_{p}}{\rho_{p} \lambda_{n}}} .
$$

The second term of (17), which also contains $S_{p}$ and $S_{n}$, is almost constant at the peak of the first term. Therefore, the output power $P$ is approximately optimized by (18) and expressed by using $Z$ as

$$
P=\frac{\xi Z G_{s} \Delta h \Delta T_{w}}{4 \ln \left(\frac{\Delta T_{\text {in }}}{\Delta T_{\text {out }}}\right)}
$$

where

$$
\xi=\frac{\ln \left(\frac{r+l}{r}\right) k}{2 \pi \lambda}=\frac{1}{1+\frac{\lambda}{\ln \left(\frac{r+l}{r}\right)}\left(\frac{1}{(r+l) h_{h}}+\frac{1}{r h_{c}}\right)}
$$

TABLE II

CHARACTERISTICS OF THE CONDENSER IN 700-MW THERMAL POWER Plant

\begin{tabular}{ll}
\hline$G_{s}(\mathrm{~kg} / \mathrm{s})$ & $4.17 \times 10^{2}$ \\
$\Delta h(\mathrm{~J} / \mathrm{kg})$ & $2.42 \times 10^{6}$ \\
$C_{w}(\mathrm{~J} / \mathrm{kg} \cdot \mathrm{K})$ & $4.18 \times 10^{3}$ \\
$T_{h}\left({ }^{\circ} \mathrm{C}\right)$ & 33 \\
$T_{c}(0)\left({ }^{\circ} \mathrm{C}\right)$ & 17 \\
$T_{c}(L)\left({ }^{\circ} \mathrm{C}\right)$ & 24 \\
$r(\mathrm{~m})$ & 0.02 \\
\hline
\end{tabular}

and (8) is rewritten by introducing (18) as

$$
\lambda=\frac{\lambda_{p} \sqrt{\rho_{p} \lambda_{n}}+\lambda_{n} \sqrt{\rho_{n} \lambda_{p}}}{\sqrt{\rho_{p} \lambda_{n}}+\sqrt{\rho_{n} \lambda_{p}}} .
$$

Because $0<\xi \leq 1$, the output power $P$ becomes the maximum when $\xi=1$. In an ideal case that $\xi$ equals to 1 , the output power takes the ideal value $P_{\text {ideal }}$

$$
P_{\text {ideal }}=\frac{Z G_{s} \Delta h \Delta T_{w}}{4 \ln \left(\frac{\Delta T_{\text {in }}}{\Delta T_{\text {out }}}\right)}
$$

$\xi$ becomes the larger by adopting thermoelements with the smaller thermal conductivity $\lambda$ and the thicker module $l$, or by increasing the heat transfer coefficients $h_{h}$ or $h_{c}$. As shown in (19) and (22), $\xi$ is the ratio of $P$ and $P_{\text {ideal }}$. Hence, $\xi$ can be defined as dimensionless output power.

\section{Calculation Results}

\section{A. Application to Practical Limitations}

In this subsection, the output power and the condenser size will be analyzed as functions of the module thickness and the heat transfer coefficients.

For concrete calculation, the numerical values are evaluated as listed in Table II. They were derived from the representative values of a thermal power plant of $700 \mathrm{MW}$. The latent heat $\Delta h$ is the difference between the enthalpy of saturated vapor and that of saturated water at $33^{\circ} \mathrm{C}$. Considering environment, the coolant temperature increment $\Delta T_{w}\left(=T_{c}(L)-T_{c}(0)\right)$ is regulated to be $7^{\circ} \mathrm{C}$ in Japan.

The heat transfer coefficient of vapor $h_{h}$ can be estimated from the Nusselt number for film condensation on horizontal tube bundles [6], and it would be $10-30 \mathrm{~kW} / \mathrm{m}^{2} \cdot \mathrm{K}$.

Assuming that the number of coolant tubes is 10000 , the Reynolds number becomes $1.14 \times 10^{5}$, and the heat transfer coefficient of coolant $h_{c}$ can be determined from the Nusselt number for turbulence flow in tubes. From the Petukov's equation [7], $h_{c}$ was calculated to be $10 \mathrm{~kW} / \mathrm{m}^{2} \cdot \mathrm{K}$.

First, the output power $P$ is shown in Fig. 4 as functions of the vapor heat transfer coefficient $h_{h}$ and the module thickness $l$. The output power $P$ becomes greater by increasing $h_{h}$ and $l$, and approaches $P_{\text {ideal }}(=201 \mathrm{~kW})$. The increase of $h_{h}$ and $l$ makes the junction temperature difference bigger and then enhances the output power $P$. However, the usage of the thick module results in expansion of condenser size. This will be discussed later.

Second, the total coolant tube length $L$ is shown in Fig. 5. The coolant tube length $L$ becomes larger as the module thickness $l$ 


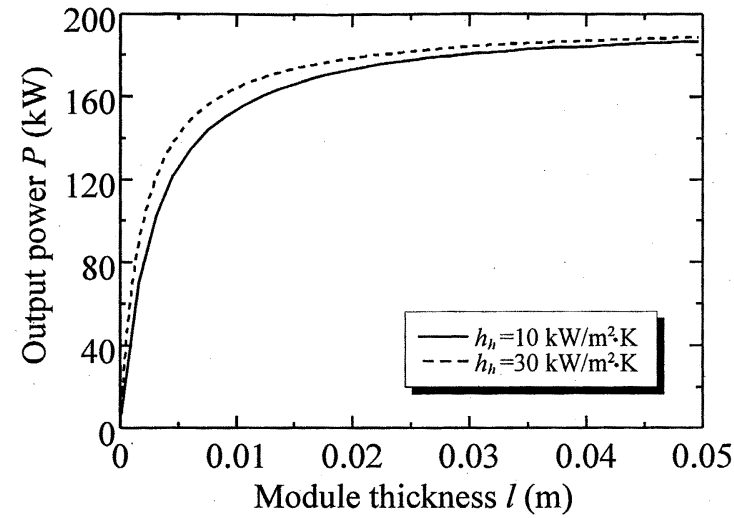

Fig. 4. Output power $P$ as functions of the vapor heat transfer coefficient $h_{h}$ and the module thickness $l$.

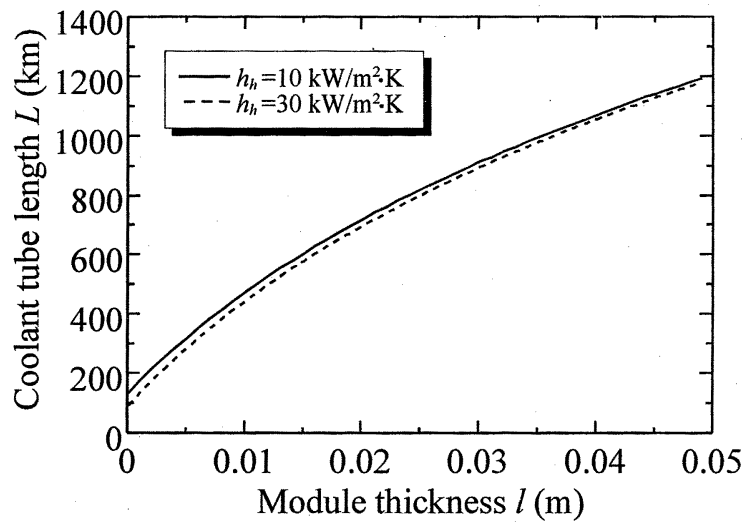

Fig. 5. Coolant tube length $L$ as functions of the vapor heat transfer coefficient $h_{h}$ and the module thickness $l$.

increases, and $L$ becomes shorter as the vapor heat transfer coefficient $h_{h}$ increases. The thicker module hinders heat transportation. As a result, the coolant tube length $L$ has to be extended to absorb all of the latent heat. On the contrary, the increase of $h_{h}$ accelerates the heat transfer and diminishes $L$.

Let us compare the coolant tube length $L$ obtained here with the actual copper tube. When the copper tube thickness $l_{C u}$ is $0.001 \mathrm{~m}$, the copper tube length $L_{C u}$ becomes $131 \mathrm{~km}\left(h_{h}=\right.$ $\left.10 \mathrm{~kW} / \mathrm{m}^{2} \cdot \mathrm{K}\right)$ or $89 \mathrm{~km}\left(h_{h}=30 \mathrm{~kW} / \mathrm{m}^{2} \cdot \mathrm{K}\right)$.

The volume of condenser is here evaluated simply by the coolant tube length $L$ and the module thickness $l$ as

$$
\pi(r+l)^{2} L .
$$

Dividing this by the copper tube volume $\pi\left(r+l_{C u}\right)^{2} L_{C u}$, the nondimensional condenser volume $v^{*}$ is defined

$$
v^{*}=\frac{\pi(r+l)^{2} L}{\pi\left(r+l_{C u}\right)^{2} L_{C u}}
$$

$v^{*}$ is shown in Fig. 6. In order to suppress $v^{*}$ under 10, for example, the module thickness $l$ should be lowered below 0.01 $\mathrm{m}$.

Table III summarizes the evaluations mentioned before. Around $150 \mathrm{~kW}$ of electricity can be generated simply by attaching the module of a few millimeters. The dimensionless output power $\xi$ is $0.6-0.8$. Although there is still a room

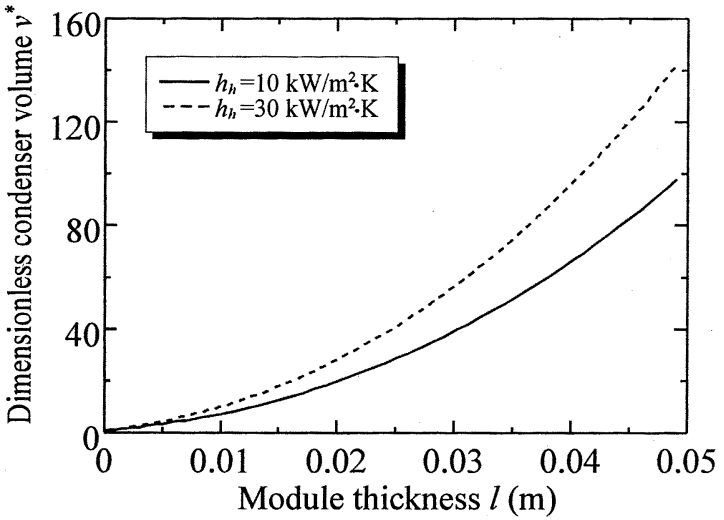

Fig. 6. Dimensionless condenser volume $v^{*}$ as functions of the vapor heat transfer coefficient $h_{h}$ and the module thickness $l$.

TABLE III Results CAlculated for FeAlSi-FeAl Module

\begin{tabular}{cccccc}
\hline $\begin{array}{c}l \\
(\mathrm{~m})\end{array}$ & $\begin{array}{c}h_{h} \\
\left(\mathrm{~kW} / \mathrm{m}^{2} \cdot \mathrm{K}\right)\end{array}$ & $\begin{array}{c}P \\
(\mathrm{~kW})\end{array}$ & $\begin{array}{c}L \\
(\mathrm{~km})\end{array}$ & $\begin{array}{c}v^{*} \\
(-)\end{array}$ & $\begin{array}{c}\xi \\
(-)\end{array}$ \\
\hline 0.005 & 10 & 126 & 318 & 3.4 & 0.63 \\
0.010 & 10 & 154 & 472 & 7.3 & 0.76 \\
\hline 0.005 & 30 & 141 & 279 & 4.4 & 0.70 \\
0.010 & 30 & 164 & 443 & 10.1 & 0.82 \\
\hline
\end{tabular}

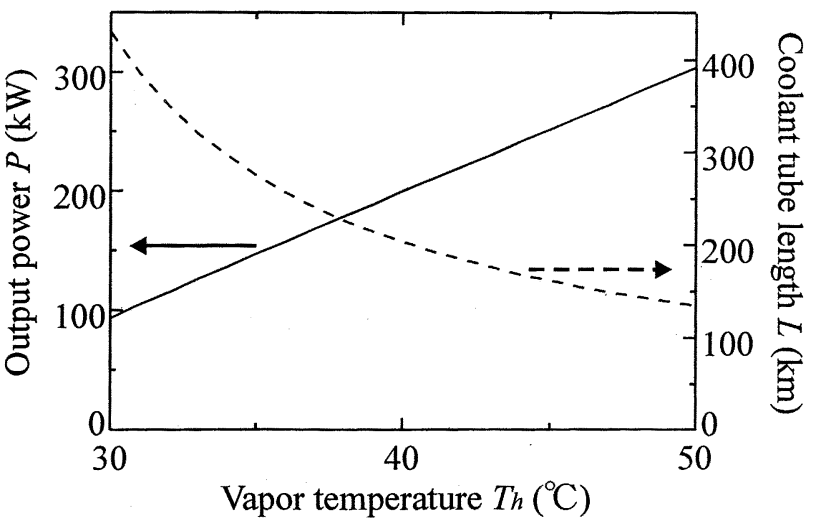

Fig. 7. Output power $P$ and coolant tube length $L$ as a function of vapor temperature $T_{h}$.

to improve the output power, a good thermal conductivity of Fe-based module makes it difficult to increase the output power.

\section{B. Possible Improvement}

Some improvements are available by introducing some assumptions. For example, the output power can be improved if a larger temperature difference is applied to the modules. Fig. 7 shows the output power $P$ and the coolant tube length $L$ as a function of the vapor temperature $T_{h}$, which was fixed at $33^{\circ} \mathrm{C}$. Here, the module length $l$ and the vapor heat transfer coefficient $h_{h}$ are set at $0.005 \mathrm{~m}$ and $10 \mathrm{~kW} / \mathrm{m}^{2} \cdot \mathrm{K}$, respectively. The latent heat $\Delta h$ is assumed to be constant since it changes only by $2 \%$ in our temperature region of $T_{h}$. When the vapor temperature $T_{h}$ rises up to $50^{\circ} \mathrm{C}$, the output power $P$ is almost tripled compared with that for $T_{h}=30^{\circ} \mathrm{C}$. At the same time, the coolant tube length $L$ strikingly decreases, because the increase of the vapor temperature $T_{h}$ enhances the heat transfer between the vapor and the coolant. 


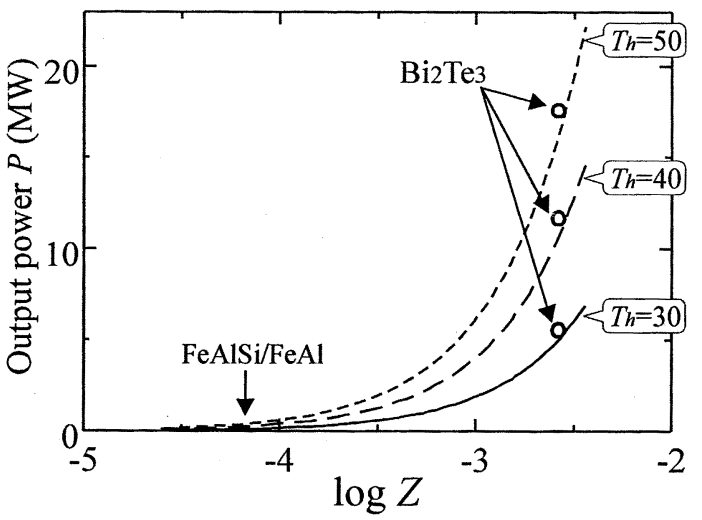

Fig. 8. Output power $P$ as functions of vapor temperature $T_{h}$ and figure of merit $Z$ in logarithmic scale.

Second, the relationship between the output power $P$ and the figure of merit $Z$ is studied. The material parameter $Z$ is manipulated by changing only the relative Seebeck coefficient $\Delta \alpha$, as a matter of convenience. The thermal conductivities $\lambda_{p}$ and $\lambda_{n}$ are fixed at $5 \mathrm{~W} / \mathrm{m} \cdot \mathrm{K}$, and the resistivities $\rho_{p}$ and $\rho_{n}$ are fixed at $5 \mu \Omega \cdot \mathrm{m}$. Calculation results are shown in Fig. 8. As expected, materials with higher $Z$ can produce larger electricity. For comparison, the figure of merit $Z$ for $\mathrm{Bi}_{2} \mathrm{Te}_{3}$ module, about $2.6 \times 10^{-3}[8]$, and their other physical parameters [8] are used for precise evaluation. $\mathrm{Bi}_{2} \mathrm{Te}_{3}$ can generate power of $5.5 \mathrm{MW}$, $11.7 \mathrm{MW}$, and $17.6 \mathrm{MW}$ for $T_{h}=30^{\circ} \mathrm{C}, 40^{\circ} \mathrm{C}$ and $50^{\circ} \mathrm{C}$, respectively as shown in Fig. 8.

Our approach suggested here does not consider the Jule heat and Peltier effect. These are vital for high performance materials such as $\mathrm{Bi}_{2} \mathrm{Te}_{3}$. According to more detailed numerical solution, as we will report separately, the real output power is about $25 \%$ less than that calculated by this analytical method in the case of $\mathrm{Bi}_{2} \mathrm{Te}_{3}$ module.

\section{CONCLUSION}

Thermoelectric conversion can generate a great deal of electricity even from the minute temperature difference without any unfavorable effect on the enviroment. The application of thermoelectric conversion to condensers in the steam-based power plants was proposed and analyzed. Using the theoretical approach of heat conduction in the cylinder wall, the mathematical function of thermoelectric output power $P$ could be deduced. The module thickness, module thermal conductivity, and heat transfer coefficients affected the output power $P$, when the thermoelectric materials were fixed and their cross-section was optimized. These factors coming from the module design were summarized by introducing the nondimensional output power $\xi$. The module construction using Fe-based alloys is much easier, but the usage of $\mathrm{Bi}_{2} \mathrm{Te}_{3}$ generates a few times larger electricity.

\section{REFERENCES}

[1] K. Ono and R. O. Suzuki, "Thermoelectric power generation: Converting low-grade heat into electricity," J. Met., vol. 50, no. 12, pp. 49-51, Dec. 1998.

[2] A. F. Ioffe, Semiconductor Thermoelements, and Thermoelectric Cooling. London, U.K.: Infosearch, 1957.

[3] R. R. Heikes and R. W. Ure Jr., Thermoelectricity: Science and Engineering. New York: Intescience Publishers, 1961.

[4] K. Ono, M. Kado, and R. O. Suzuki, "Thermoelectric properties of the $\mathrm{Fe}-\mathrm{Al}$ and $\mathrm{Fe}-\mathrm{Al}-\mathrm{Si}$ alloys for thermoelectric generation utilizing lowtemperature heat sources," Steel Research, vol. 69, no. 9, pp. 387-390, Sept. 1998

[5] R. B. Bird, W. E. Stewart, and E. N. Lightfoot, Transport Phenomena. New York: Wiley, 1960, p. 287.

[6] T. Hujii and K. Oda, "Correlation equation of heat transfer for condensate inundation on horizontal tube bundles," J. Jpn. Inst. Met., vol. 52, no. 474, pp. 822-826, Feb. 1986.

[7] B. S. Petukov, Advances in Heat Transfer. New York: Academic Press, 1970, vol. 6, p. 523.

[8] H. Scherrer and S. Scherrer, Thermoelectrics, D. M. Rowe, Ed. New York: CRC Press, 1995, p. 215.

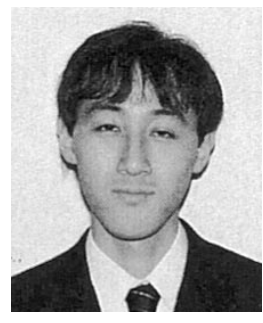

Takashi Kyono is currently pursuing the Master's degree in Energy Science at the Department of Energy Science and Technology, Kyoto University, Kyoto, Japan.

His reserch is focused mainly on engineering of thermoelectric generation.

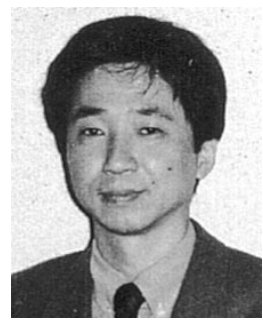

Ryosuke O. Suzuki received the D.Eng. degree from Kyoto University, Kyoto, Japan, in 1984.

Currently, he is an Associate Professor at the Depertment of Energy Science and Technology, Kyoto University.

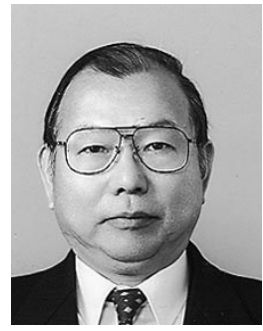

Katsutoshi Ono received the D.Sc. degree from the University of Paris, France, in 1966.

Currently, he is an Emeritus Professor at Kyoto University, Kyoto, Japan. 